\title{
Épocas e parcelamentos da adubação nitrogenada aplicada em cobertura na cultura do feijoeiro, grupo comercial preto e carioca, em semeadura direta
}

\author{
Time and partition of nitrogen fertilization side-dressed applied on bean crop, black and carioca \\ commercial group, in direct sowing
}

\author{
Antônio Luis Santi ${ }^{I}$ Claudir José Basso ${ }^{\mathrm{II}}$ Fabiane Pinto Lamego ${ }^{\mathrm{II}}$ Lisandra Pinto Della Flora ${ }^{\mathrm{III}}$ \\ Telmo Jorge Carneiro Amado ${ }^{\mathrm{IV}}$ Maurício Roberto Cherubin ${ }^{\mathrm{v}}$
}

\section{RESUMO}

O trabalho teve como objetivo avaliar qual a melhor época de aplicação do $\mathrm{N}$ e qual o parcelamento da adubação nitrogenada a ser adotado no sistema plantio direto, em cultivares de feijoeiro do grupo comercial preto e carioca. O experimento foi conduzido no município de Jaboticaba - RS. Os tratamentos constaram da aplicação de $N$, utilizando como fonte nitrogenada a ureia, em uma única dose (100\%), nas épocas: emergência das plântulas, aos 7, 14,21, 28 e 35 dias após emergência (DAE), e das seguintes combinações de parcelamentos: $50 \%+50 \%, 30 \%+70 \%$ e $70 \%+30 \%$ da dose em cada época, totalizando 36 tratamentos. As variáveis avaliadas foram: estatura de plantas (cm); número de nós da haste principal; número de nós $m^{-2}$; número de legumes planta $^{-1}$; número de legumes $\mathrm{m}^{-2}$; número de grãos legume ${ }^{-1}$; altura da base do primeiro legume ao solo; altura de inserção do primeiro legume; e massa de 100 grãos e produtividade de grão. Conclui-se que a melhor época de aplicação e parcelamento foi $30 \%$ da dose aos $7 D A E+70 \%$ aos 35DAE, diferindo das sugestões propostas pelas atuais recomendações de $N$ para a cultura do feijoeiro. Além disso, a aplicação de $100 \%$ da dose de $N$, na emergência das plântulas, apresentou as menores produtividades, não se mostrando promissora para os grupos de feijoeiro estudados.

Palavras-chave: Phaseolus vulgaris L., adubação nitrogenada, produtividade.

\section{ABSTRACT}

The research had as objective to evaluate what is the better time of $N$ application and what is the partition of nitrogen fertilization to be used in no tillage system, in bean cultivars of black and carioca commercial groups. The experiment was conducted in Jaboticaba city - RS. The treatments were $N$ application, using urea as nitrogen source, in one dose (100\%) in the time: seedling emergence, at 7, 14,21, 28 and 35 days after emergence (DAE) and according to the following partition combinations: $50 \%+50 \%, 30 \%+70$ and $70 \%+30 \%$ of the dose in each time, totalizing 36 treatments. The variables evaluated were: plant height $(\mathrm{cm})$; number of nodes of principal stem; number of nodes $\mathrm{m}^{-2}$; number of pods plant ${ }^{-1}$; number of pods $\mathrm{m}^{-2}$; number of grains pod $^{-1}$; base height of the first pod from the soil; insertion height of the first pod; and 100 grains mass and productivity. It is concluded that the better time of application and partition was $30 \%$ of the dose at 7DAE $+70 \%$ at 35DAE differing of the suggestions proposed by the actual $N$ recommendations for bean crop. And that the application of $100 \%$ of the N dose, at the seedlings emergence, presented the lowest productivity does not showing be promising to the bean groups studied.

Key words: Phaseolus vulgaris L., nitrogen fertilization, productivity.

\section{INTRODUÇÃO}

No Rio Grande do Sul (RS), os trabalhos que envolvem práticas de manejo referentes ao momento e forma da disponibilização do nitrogênio (N) e embasam as atuais recomendações para a cultura do feijoeiro ainda permanecem restritos a trabalhos gerados em condições de semeadura convencional na década de 70 .

'Departamento de Ciências Agronômicas e Ambientais, Centro de Educação Superior Norte do Rio Grande do Sul (CESNORS), Universidade Federal de Santa Maria (UFSM), 98400-000, Frederico Westphalen, RS, Brasil. E-mail: santi_pratica@yahoo.com.br. Autor para correspondência.

IIDepartamento de Ciências Agronômicas e Ambientais, CESNORS, UFSM, Frederico Westphalen, RS, Brasil.

${ }^{\text {IIIC} C o l e ́ g i o ~ A g r i ́ c o l a ~ d e ~ F r e d e r i c o ~ W e s t p h a l e n ~(C A F W), ~ U F S M, ~ F r e d e r i c o ~ W e s t p h a l e n, ~ R S, ~ B r a s i l . ~}$

${ }^{\text {IV }}$ Departamento de Solos, Centro de Ciências Rurais (CCR), UFSM, Santa Maria, RS, Brasil.

`Programa de Pós-graduação em Solos e Nutrição de Plantas, Escola Superior de Agricultura "Luiz de Queiroz" (ESALQ), Universidade de São Paulo (USP), Piracicaba, SP, Brasil. 
No feijoeiro, em condições ambientais adequadas, a simbiose com bactérias do gênero Rhizobium consegue suprir em parte a adubação nitrogenada, mas, segundo a COMISSÃO TÉCNICA SUL-BRASILEIRA DE FEIJÃO (2009), o feijoeiro, mesmo sendo uma leguminosa capaz de fixar $\mathrm{N}$ atmosférico via associação simbiótica, naturalmente ou por meio de inoculação, não consegue suprir totalmente a demanda de $\mathrm{N}$ quando se visa a altas produtividades de grãos (acima de 2,0 $\mathrm{Mg} \mathrm{ha}^{-1}$ ).

Dessa forma, os produtores têm realizado aplicação de $\mathrm{N}$ por meio de fertilizantes nitrogenados em cobertura, baseando-se em experiências de campo ou na proposta da CQFS-RS/SC (2004), em que o $\mathrm{N}$ em cobertura deve ser aplicado quando as plantas estiverem em $\mathrm{V}_{3}$ e $\mathrm{V}_{4}$ (1 a 3 trifólios), o que coincide entre 15 e 30DAE. Porém, mesmo a matéria orgânica sendo uma fonte fundamental de nutrientes para as plantas, disponibilizando elementos como o $\mathrm{N}$, fósforo e enxofre, e de ser o critério básico para as recomendações de $\mathrm{N}$ no feijoeiro, esse índice tem tido rejeição entre os produtores que buscam altos rendimentos, já que uma série de fatores como textura do solo, temperatura, umidade, acidez e atividade microbiana pode influenciar na mineralização do $\mathrm{N}$ (BAYER \& MIELNICZUK, 2008). NICOLOSO (1989), trabalhando com doses de N (ausência de N, 30 e $60 \mathrm{~kg} \mathrm{ha}^{-1}$ ) e épocas de aplicação (semeadura, 15 e 30DAE) e inoculação, atribuiu a falta de resposta da cultura à adubação nitrogenada ao teor de matéria orgânica no solo $(3,5 \%)$.

Autores como ROSOLEM \& MARUBAYASHI (1994) colaboram com essa justificativa, definindo o feijoeiro como uma planta com ciclo curto e sistema radicular superficial, o que determina que os nutrientes, em especial o $\mathrm{N}$, devem ser disponibilizados às plantas em época adequada e de modo que ainda favoreça o aumento do número de legumes por planta, isto é, até o início do florescimento, mas que é necessário estabelecer as estratégias de manejo do $\mathrm{N}$ aplicado em cobertura, abrangendo fontes, doses, épocas e parcelamento do N. Embora alguns trabalhos objetivem avaliar os efeitos da interação doses de $\mathrm{N}$ e inoculação com Rhizobium (SOUZA et al., 2011), quando se deseja a interpretação de respostas do feijoeiro a épocas e parcelamento do N, a opção é não inocular as sementes, como verificada em vários trabalhos CARVALHO et al. (2003), SANTI et al. (2006), SORATTO et al. (2006), ARF et al. (2011) e SANT'ANA et al. (2011). ROSOLEM (1987) diz que a aplicação deve ser realizada, no máximo, até 36DAE, enquanto que SORATTO et al. (2001) verificaram que a aplicação do $\mathrm{N}$ aos 15DAE proporcionou maior produtividade de massa seca no florescimento e também maior produtividade de grãos. SORATTO et al. (2006) comprovaram essa tendência na produtividade com a aplicação de $\mathrm{N}$ aos 15DAE, no entanto, não diferiu da aplicação de $\mathrm{N}$ em cobertura aos 30DAE.

Embora alguns autores como HUNGRIA et al. (1985) tenham observado um aumento sensível na eficiência de utilização do fertilizante nitrogenado pela cultura do feijoeiro no período de 20 a 40DAE, aplicações de $\mathrm{N}$ aos 7DAE podem se constituir como importante estratégia de manejo na semeadura direta. Entretanto, trabalhos mais atuais envolvendo épocas não contemplam aplicações de $\mathrm{N}$ antes de 15DAE. Esse comportamento, embora necessite novos estudos, poderá possibilitar uma maior flexibilização no momento da realização da adubação nitrogenada de cobertura em áreas de semeadura direta para o feijoeiro.

SANTI et al. (2006), trabalhando com adubação nitrogenada na cultura do feijoeiro em plantio convencional, não encontraram interação entre a época da adubação nitrogenada e cultivares. O melhor rendimento de grãos foi obtido por meio da aplicação de $100 \%$ da adubação nitrogenada aos 21 dias após a emergência. A aplicação do $\mathrm{N}$ após os 28DAE não apresentou resultados favoráveis à obtenção de elevados rendimentos de grãos.

Além das divergências entre literaturas quanto a melhor época de aplicação do $\mathrm{N}$, as recomendações que suportam o manejo desse nutriente no feijoeiro, no RS, sugeridos pela COMISSÃO TÉCNICA SUL-BRASILEIRA DE FEIJÃO (2009) e CQFS-RS/SC (2004) não contemplam as cultivares de feijoeiro dos diferentes grupos comerciais, mesmo admitindo que existam diferenças na duração do ciclo.

Nesse contexto, o trabalho teve por objetivo verificar qual a melhor época de aplicação do $\mathrm{N}$ e qual o parcelamento da adubação nitrogenada que deverá ser adotado no sistema plantio direto, em cultivares de feijoeiro do grupo comercial preto e carioca, visando a altas produtividades.

\section{MATERIAL E MÉTODOS}

O experimento foi conduzido em uma propriedade rural localizada no município de Jaboticaba, região Norte do RS, e altitude média de $634 \mathrm{~m}$. A localidade pertence à região climática do Planalto Médio, onde segundo a classificação de Köeppen, o clima é do tipo Cfa - temperado chuvoso, com precipitação média anual elevada, geralmente entre 1.800 e $2.100 \mathrm{~mm}$, bem distribuída ao longo do ano e subtropical do ponto de vista

Ciência Rural, v.43, n.5, mai, 2013. 
térmico. A temperatura média anual é em torno $18^{\circ} \mathrm{C}$, com máximas no verão podendo atingir $41^{\circ} \mathrm{C}$ e mínimas no inverno atingindo valores inferiores a $0^{\circ} \mathrm{C}$ (MORENO, 1961). Durante a condução do experimento, a precipitação total foi de $575 \mathrm{~mm}$, bem distribuídos, e as temperaturas extremas não foram superiores a $31^{\circ} \mathrm{C}$ (máxima) nem inferiores a $14^{\circ} \mathrm{C}$ (mínima), conforme figura 1.

O solo da área experimental é classificado como Latossolo Vermelho distrófico típico (EMBRAPA, 2006), cujo manejo envolve semeadura direta há quinze anos, cultivado tradicionalmente soja e milho, no verão, e trigo e aveia preta, no inverno. A amostragem de solo na camada de $0,10 \mathrm{~m}$, para avaliação das características químicas, mostrou os seguintes valores: $\mathrm{pH}$ em água 5,$4 ; 5,5 \mathrm{mg} \mathrm{dm}^{-3} \mathrm{de}$ fósforo; $74 \mathrm{mg} \mathrm{dm}^{-3}$ de potássio; $3,6 \%$ de matéria orgânica; zero de alumínio; $5,5 \mathrm{cmol}_{\mathrm{c}} \mathrm{L}^{-1}$ de cálcio; $2,4 \mathrm{cmol}_{\mathrm{c}} \mathrm{L}^{-1}$ de magnésio; CTC efetiva de $8,1 \mathrm{cmol}_{\mathrm{c}}$ $\mathrm{L}^{-1}$ e saturação de bases de $65 \%$.

$\mathrm{O}$ delineamento experimental foi de blocos ao acaso, com parcela subdividida e quatro repetições, em esquema fatorial (épocas e parcelamento). Os tratamentos foram constituídos pelas épocas: $100 \%$ do $\mathrm{N}$ na emergência das plântulas; aos $7 ; 14 ; 21 ; 28$ e 35DAE, e pelos parcelamentos: $30 \%+70 \%$ da dose;
$50 \%+50 \%$ da dose e $70 \%+30 \%$ da dose, combinados nas cinco épocas após a emergência das plântulas, totalizando 36 tratamentos.

Por ocasião da semeadura, todos os tratamentos receberam $300 \mathrm{~kg} \mathrm{ha}^{-1}$ de fertilizante mineral NPK da fórmula 5-20-20. A adubação nitrogenada de cobertura foi realizada a lanço, utilizando-se como fonte de $\mathrm{N}$ a ureia (45\% de $\mathrm{N}$ ), na dose de $70 \mathrm{~kg} \mathrm{ha}^{-1}$ de N. Tanto a adubação de base como de cobertura foram definidas em concordância com as recomendações da CQFS-RS/SC (2004), para a cultura do feijoeiro. Visando a isolar os efeitos da aplicação de $\mathrm{N}$ via fertilizante nitrogenado em cobertura na cultura, não foi procedida à inoculação das sementes tal como descrevem CARVALHO et al. (2003), SANTI et al. (2006), SORATTO et al. (2006), ARF et al. (2011) e SANT'ANA et al. (2011).

As cultivares estudadas foram a 'TPS Nobre', de tipo II, indeterminado com ramificação ereta e fechada, na população de 300.000 plantas $\mathrm{ha}^{-1}$, e a cultivar 'Pérola', de tipo III, indeterminado com ramificação aberta, na população de 260.000 plantas $\mathrm{ha}^{-1}$, ambas no sistema semeadura direta, sob palhada de aveia preta $\left(5,0 \mathrm{Mg} \mathrm{ha}^{-1}\right)$. As parcelas foram constituídas de oito linhas espaçadas $0,45 \mathrm{~m}$ com $6,0 \mathrm{~m}$ de comprimento. A área útil para a

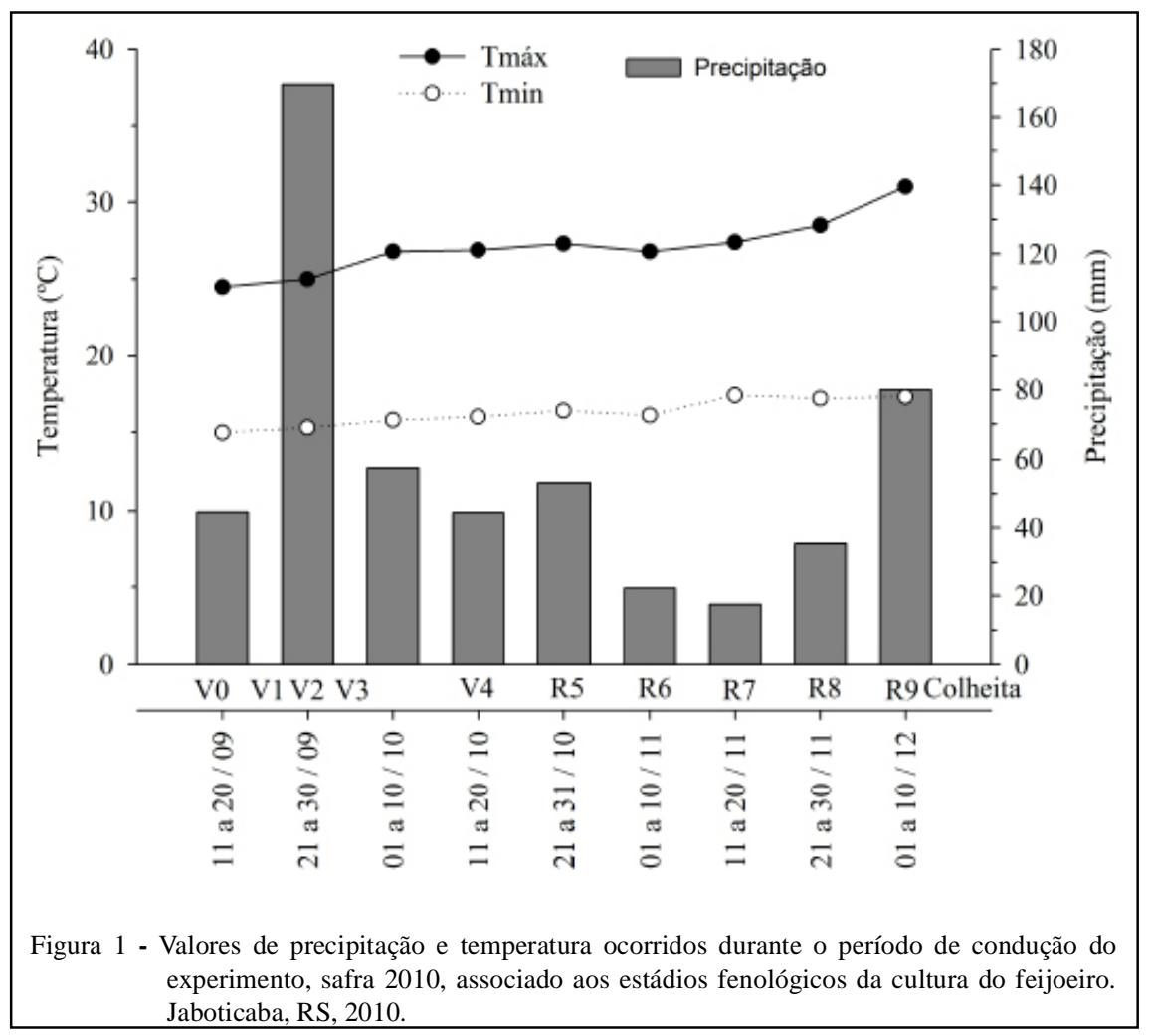

Ciência Rural, v.43, n.5, mai, 2013. 
avaliação da produtividade foi considerada as quatro linhas centrais de cada parcela, descartando-se $1,0 \mathrm{~m}$ de cada extremidade. A semeadura foi realizada mecanicamente e a data da emergência foi considerada quando $50 \%$ das plântulas haviam emergido, seis dias após a semeadura. Durante o ciclo da cultura, foram realizados os tratos culturais e fitossanitários, de acordo com as recomendações da COMISSÃO TÉCNICA SUL-BRASILEIRA DE FEIJÃO (2009).

Em cada parcela, por ocasião da colheita, foram amostradas dez plantas para a determinação das seguintes variáveis: estatura de plantas $(\mathrm{cm})$; número de nós da haste principal planta-1; número de nós $\mathrm{m}^{-2}$; número de legumes planta ${ }^{-1}$; número de legumes $\mathrm{m}^{-2}$; número de grãos legume ${ }^{-1}$; altura da base do primeiro legume ao solo; altura de inserção do primeiro legume e massa de 100 grãos. Para análise da produtividade, as plantas da área útil foram arrancadas, trilhadas, e a umidade da massa de grãos, corrigida para $130 \mathrm{~g} \mathrm{~kg}^{-1}$ de umidade. Os dados foram submetidos à análise da variância e as médias comparadas pelo teste Scott e Knott a 5\% de probabilidade de erro, utilizando o programa estatístico SOC (EMBRAPA, 1997).

\section{RESULTADOS}

A análise da variância demonstrou que os dados referentes aos componentes de rendimento dos tratamentos estudados não foram significativos pelo teste $\mathrm{F}(5 \%)$, justificando a comparação entre cultivares, utilizando os valores médios (Tabela 1). Esses resultados concordam com SORATTO et al. (2006) e ARF et al. (2011), que avaliaram épocas e doses, e fonte e épocas de aplicação de $\mathrm{N}$ em feijoeiro sob sistema plantio direto, respectivamente, também verificaram baixa de respostas nos componentes de rendimento em função dos tratamentos aplicados. Dessa forma, verificou-se que houve diferença apenas entre as cultivares utilizadas. A superioridade da cultivar 'Pérola', quando comparada com a cultivar 'TPS Nobre', para estatura de plantas não se refletiu em maior altura de inserção do primeiro legume e altura da base do primeiro legume. Esses resultados demonstram que a utilização da estatura de planta como único parâmetro para a escolha de genótipos mais adaptados à colheita mecanizada merece cautela, uma vez, que as alturas de inserção do primeiro legume e da base do primeiro legume não apresentaram a mesma resposta da estatura de planta. Corroborando os resultados obtidos, COIMBRA et al. (2000) e CABRAL et al. (2011) também verificaram baixas correlações entre estatura de planta e altura de inserção do primeiro legume. No entanto, nas condições deste experimento, a cultivar 'TPS Nobre', pelas alturas de inserção do primeiro legume e base do primeiro legume, associado ao porte semi-ereto, permitiria a colheita mecanizada.

Os componentes do rendimento como número de grãos legume ${ }^{-1}$, número de legumes planta ${ }^{-1}$, número de legumes $\mathrm{m}^{-2}$ e número de nós $\mathrm{m}^{-2}$ refletem uma superioridade da cultivar 'TPS Nobre', porém, para a massa de 100 grãos, a cultivar 'Pérola' apresentou valor médio 49,6\% superior. A massa de 100 grãos manteve-se semelhante àquela descrita para essas cultivares pela COMISSÃO ESTADUAL DE PESQUISA DE FEIJÃO (2001) de 18,4g ('TPS Nobre') e 27,0g ('Pérola'), respectivamente.

Considerando que as cultivares testadas possuem diferenças marcantes e que estes são os componentes mais importantes na definição da

Tabela 1 - Médias e coeficientes de variação (CV\%) das variáveis: estatura de plantas, altura de inserção da primeira vagem, altura da base da primeira vagem, número de grãos vagens ${ }^{-1}$, número de vagens planta ${ }^{-1}$, número de vagens $\mathrm{m}^{-2}$, número de nós $\mathrm{m}^{-2}$, massa de 100 grãos e número de nós na haste principal das cultivares 'TPS Nobre' e 'Pérola' em função da época da aplicação e do parcelamento da adubação nitrogenada, em sistema de plantio direto. Jaboticaba, RS, 2010.

\begin{tabular}{|c|c|c|c|}
\hline Variáveis & 'TPS Nobre" & 'Pérola' & $\mathrm{CV}(\%)$ \\
\hline Estatura de planta $(\mathrm{cm})$ & $54,44 b *$ & $58,20 \mathrm{a}$ & 14,25 \\
\hline Altura de inserção do primeiro legume $(\mathrm{cm})$ & $24,25 \mathrm{a}$ & $23,14 \mathrm{~b}$ & 14,43 \\
\hline Altura da base do primeiro legume $(\mathrm{cm})$ & $16,10 \mathrm{a}$ & $14,52 b$ & 21,15 \\
\hline Número de grãos legume ${ }^{-1}$ & $5,08 \mathrm{a}$ & $3,80 \mathrm{~b}$ & 11,85 \\
\hline Número de legume planta ${ }^{-1}$ & $13,61 \mathrm{a}$ & $12,08 \mathrm{~b}$ & 24,79 \\
\hline Número de legume $\mathrm{m}^{-2}$ & $286,50 \mathrm{a}$ & $192,69 \mathrm{~b}$ & 21,21 \\
\hline Número de nós $\mathrm{m}^{-2}$ & $380,65 a$ & $286,14 b$ & 21,12 \\
\hline Massa de 100 grãos (g) & $19,60 \mathrm{~b}$ & $27,37 a$ & 5,64 \\
\hline Número de nós na haste principal & $11.44 a$ & $9,70 \mathrm{~b}$ & 7.76 \\
\hline
\end{tabular}

* Médias seguidas de mesma letra na linha não diferem entre si pelo teste de Scott \& Knott, em nível de $5 \%$ de probabilidade de erro.

Ciência Rural, v.43, n.5, mai, 2013. 
produtividade, a impossibilidade de diferenciá-las na característica produtividade sugere que os novos trabalhos sobre adubação de $\mathrm{N}$ em cobertura no feijoeiro sejam envolvendo cultivares do mesmo tipo e/ou individualizadas, além de respostas à inoculação.

O número de nós da haste principal apresentou comportamento inverso à estatura, demonstrando que diferenças nessa característica devem-se a comprimentos de entrenós diferentes, os quais foram de $6,0 \mathrm{~cm}$ e $4,8 \mathrm{~cm}$ para a cultivar 'Pérola' e para a cultivar 'TPS Nobre', respectivamente. Trabalhando com a cultivar 'Carioca', PALOMINO et al. (2000) também não encontraram diferença significativa em função das épocas de aplicação do $\mathrm{N}$ em nenhuma variável avaliada, atribuindo tal comportamento à boa fertilidade do solo, ótimo teor de fósforo, baixa acidez (ausência de alumínio trocável), alta saturação de bases e rotação, na área do experimento, com a cultura da soja.

Na tabela 2, estão apresentados os valores médios da produtividade de grãos, de acordo com a época e a forma de aplicação (única dose ou parcelada). Para a cultivar 'TPS Nobre', do grupo comercial preto, não houve diferença estatística entre os tratamentos, mesmo quando aplicado $100 \%$ do $\mathrm{N}$ na emergência das plântulas. Para a cultivar 'Pérola', grupo comercial carioca, a tendência foi muito similar, porém mostrou diferenças estatísticas e menor produtividade no tratamento $100 \%$ do $\mathrm{N}$ na emergência das plântulas. Tais resultados concordam com os obtidos por CARVALHO et al. (2003). Esses resultados também podem ser atribuídos à baixa taxa de absorção de $\mathrm{N}$ pelas plântulas de feijoeiro na emergência, devido ao pequeno crescimento radicular na fase inicial e, por consequência, maior possibilidade de perdas de $\mathrm{N}$ no solo. Além disso, esses resultados reforçam as evidências já comprovadas para outras culturas, como o milho, encontradas por BASSO \& CERETTA (2000), demonstrando ser uma atitude de risco e capaz de aumentar as chances de perdas desse nutriente mesmo em semeadura direta.

Em termos de ciclo, não houve discrepância entre as cultivares. A colheita da cultivar 'TPS Nobre' foi realizada aos 88DAE e a cultivar 'Pérola' aos 89DAE, o que demonstra que ambas tiveram comportamento similar, embora a cultivar 'TPS Nobre' seja descrita como sendo do tipo II, ciclo 93 dias, e a cultivar 'Pérola' do tipo III, ciclo de 90 dias (COMISSÃO ESTADUAL DE PESQUISA DE FEIJÃO, 2001).

A partir da análise estatística, considerando a média da produtividade entre as duas cultivares de feijoeiro, foi observado significância para os efeitos de tratamentos, sendo que a melhor época e parcelamento de $\mathrm{N}$ em cobertura foi quando se aplicou 30\% da dose aos 7DAE+70\% da dose aos 35DAE. Os tratamentos em que se disponibilizou $30 \%$ da dose aos 7DAE $+70 \%$ da dose aos 14DAE e $50 \%$ da dose aos $21 \mathrm{DAE}+50 \%$ da dose aos 28DAE apresentaram-se como a segunda melhor opção de época e parcelamento de $\mathrm{N}$ em cobertura, diferiram estatisticamente dos demais tratamentos.

Aplicações de $\mathrm{N}$ precoces, aos 7DAE precedidas por aplicações mais tardias, em torno de 35DAE, constituem-se numa importante estratégia de manejo em SSD, quando comparadas com as propostas das atuais recomendações para a cultura, apresentadas pela COMISSÃO TÉCNICA SULBRASILEIRA DE FEIJÃO (2009) e CQFS-RS/SC (2004). Isso se dá porque essas duas recomendações estão baseadas em dados gerados em condições de semeadura convencional, o que justifica a possibilidade de outras épocas de aplicação do $\mathrm{N}$ para o feijoeiro, quando em SSD, também serem eficientes do ponto de vista de rendimento de grãos, tendo em vista que as diferenças existentes entre os dois sistemas de cultivo, quanto à dinâmica deste nutriente e a taxa de mineralização da matéria orgânica em um SSD, quando da adição de $\mathrm{N}$ mineral, já foram observadas por BASSO \& CERETTA (2000) e BAYER \& MIELNICZUK (2008).

Nesse sentido, sugere-se a realização de futuras pesquisas com $\mathrm{N}$ na cultura do feijoeiro em SSD, considerando outras formas de disponibilização do $\mathrm{N}$, como a possibilidade de incorporação do $\mathrm{N}$ ao solo, visando a minimizar as perdas por volatilização e escorrimento superficial, a inclusão de semeadura sob diferentes plantas de cobertura, visando à liberação gradativa do $\mathrm{N}$, ajustando-se com os momentos de maiores demandas de $\mathrm{N}$ pelo feijoeiro, e, consequentemente, culminado em um possível aumento da eficiência no aproveitamento do $\mathrm{N}$ mineralizado. Além disso, trabalhos que avaliam os diferentes hábitos de crescimento do feijoeiro, visando a estabelecer as possíveis diferenças de resposta a época, dose e forma de aplicação de $\mathrm{N}$ em cobertura.

\section{CONCLUSÃO}

A melhor estratégia de aplicação da adubação nitrogenada em cobertura foi parcelar $30 \%$ da dose aos sete e $70 \%$ da dose aos 35 dias após a emergência para a cultivar do grupo carioca, diferindo das sugestões propostas pelas atuais recomendações para a cultura do feijoeiro. A antecipação do nitrogênio, $100 \%$ da dose na emergência das 
Épocas e parcelamentos da adubação nitrogenada aplicada em cobertura na cultura do feijoeiro, grupo comercial preto e carioca... 821

Tabela 2 - Produtividade $\left(\mathrm{kg} \mathrm{ha}^{-1}\right)$ das cultivares 'TPS Nobre' e 'Pérola' considerando a época de aplicação e o parcelamento da adubação nitrogenada. Jaboticaba, RS, 2010.

\begin{tabular}{|c|c|c|c|}
\hline Tratamentos & 'TPS Nobre' & 'Pérola' & Medias \\
\hline T1 - 100\% do N na emergência & $2.526 \mathrm{a}^{*}$ & $1.361 \mathrm{~b}$ & $1.944 \mathrm{e}$ \\
\hline $\mathrm{T} 2-100 \%$ do N 7DAE & $2.974 \mathrm{a}$ & $2.113 \mathrm{ab}$ & $2.544 d$ \\
\hline T3 - 100\% do N 14DAE & $3.012 \mathrm{a}$ & $2.306 \mathrm{ab}$ & $2.659 \mathrm{c}$ \\
\hline $\mathrm{T} 4-100 \%$ do N 21DAE & $2.807 \mathrm{a}$ & $2.417 \mathrm{a}$ & $2.613 \mathrm{~d}$ \\
\hline T5 - 100\% do N 28DAE & $2.804 \mathrm{a}$ & $2.675 \mathrm{a}$ & $2.740 \mathrm{c}$ \\
\hline T6 - 100\% do N 35DAE & $2.706 \mathrm{a}$ & $2.695 \mathrm{a}$ & $2.701 \mathrm{c}$ \\
\hline $\mathrm{T} 7-30 \%$ 7DAE + 70\% 14DAE & $2.968 \mathrm{a}$ & $2.750 \mathrm{a}$ & $2.859 \mathrm{~b}$ \\
\hline $\mathrm{T} 8-50 \%$ 7DAE + 50\% 14DAE & $2.909 \mathrm{a}$ & $2.492 \mathrm{a}$ & $2.701 \mathrm{c}$ \\
\hline $\mathrm{T} 9-70 \%$ 7DAE + 30\% 14DAE & $2.940 \mathrm{a}$ & $2.470 \mathrm{a}$ & $2.705 \mathrm{c}$ \\
\hline $\mathrm{T} 10-30 \%$ 7DAE + 70\% 21DAE & $2.944 \mathrm{a}$ & $2.233 \mathrm{ab}$ & $2.589 \mathrm{~d}$ \\
\hline $\mathrm{T} 11-50 \%$ 7DAE + 50\% 21DAE & $2.845 \mathrm{a}$ & $2.558 \mathrm{a}$ & $2.702 \mathrm{c}$ \\
\hline $\mathrm{T} 12-70 \%$ 7DAE + 30\% 21DAE & $3.036 \mathrm{a}$ & $2.544 \mathrm{a}$ & $2.790 \mathrm{c}$ \\
\hline $\mathrm{T} 13-30 \%$ 7DAE + 70\% 28DAE & $2.874 \mathrm{a}$ & $2.167 \mathrm{ab}$ & $2.521 \mathrm{~d}$ \\
\hline $\mathrm{T} 14-50 \%$ 7DAE + 50\% 28DAE & $2.866 \mathrm{a}$ & $2.421 \mathrm{a}$ & $2.644 d$ \\
\hline $\mathrm{T} 15-70 \%$ 7DAE + 30\% 28DAE & $2.990 \mathrm{a}$ & $2.565 \mathrm{a}$ & $2.778 \mathrm{c}$ \\
\hline $\mathrm{T} 16-30 \%$ 7DAE + 70\% 35DAE & $3.108 \mathrm{a}$ & $2.724 a$ & $2.916 \mathrm{a}$ \\
\hline $\mathrm{T} 17-50 \%$ 7DAE + 50\% 35DAE & $2.902 \mathrm{a}$ & $2.646 \mathrm{a}$ & $2.774 \mathrm{c}$ \\
\hline $\mathrm{T} 18-70 \%$ 7DAE + 30\% 35DAE & $2.821 \mathrm{a}$ & $2.642 \mathrm{a}$ & $2.732 \mathrm{c}$ \\
\hline T19-30\% 14DAE + 70\% 21DAE & $3.093 \mathrm{a}$ & $2.413 \mathrm{a}$ & $2.753 \mathrm{c}$ \\
\hline $\mathrm{T} 20-50 \% 14 \mathrm{DAE}+50 \% 21 \mathrm{DAE}$ & $2.842 \mathrm{a}$ & $2.538 \mathrm{a}$ & $2.690 \mathrm{c}$ \\
\hline $\mathrm{T} 21-70 \%$ 14DAE + 30\% 21DAE & $2.719 \mathrm{a}$ & $2.723 \mathrm{a}$ & $2.721 \mathrm{c}$ \\
\hline $\mathrm{T} 22-30 \% 14 \mathrm{DAE}+70 \% 28 \mathrm{DAE}$ & $2.863 \mathrm{a}$ & $2.281 \mathrm{ab}$ & $2.572 \mathrm{~d}$ \\
\hline $\mathrm{T} 23-50 \% 14 \mathrm{DAE}+50 \% 28 \mathrm{DAE}$ & $2.743 \mathrm{a}$ & $2.121 \mathrm{ab}$ & $2.432 \mathrm{~d}$ \\
\hline $\mathrm{T} 24-70 \%$ 14DAE + 30\% 28DAE & $2.972 \mathrm{a}$ & $2.582 \mathrm{a}$ & $2.777 \mathrm{c}$ \\
\hline $\mathrm{T} 25-30 \%$ 14DAE + 70\% 35DAE & $2.960 \mathrm{a}$ & $2.409 \mathrm{ab}$ & $2.684 \mathrm{c}$ \\
\hline $\mathrm{T} 26-50 \%$ 14DAE + 50\% 35DAE & $2.893 \mathrm{a}$ & $2.625 \mathrm{a}$ & $2.759 \mathrm{c}$ \\
\hline $\mathrm{T} 27-50 \%$ 14DAE + 50\% 35DAE & $2.907 \mathrm{a}$ & $2.531 \mathrm{a}$ & $2.719 \mathrm{c}$ \\
\hline $\mathrm{T} 28-30 \% 21 \mathrm{DAE}+70 \% 28 \mathrm{DAE}$ & $2.748 \mathrm{a}$ & $2.781 \mathrm{a}$ & $2.765 \mathrm{c}$ \\
\hline $\mathrm{T} 29-50 \% 21 \mathrm{DAE}+50 \% 28 \mathrm{DAE}$ & $2.846 \mathrm{a}$ & $2.857 \mathrm{a}$ & $2.852 \mathrm{~b}$ \\
\hline $\mathrm{T} 30-70 \% 21 \mathrm{DAE}+30 \% 28 \mathrm{DAE}$ & $2.740 \mathrm{a}$ & $2.708 \mathrm{a}$ & $2.724 \mathrm{c}$ \\
\hline $\mathrm{T} 31-30 \% 21 \mathrm{DAE}+70 \% 35 \mathrm{DAE}$ & $2.937 \mathrm{a}$ & $2.349 \mathrm{ab}$ & $2.643 \mathrm{~d}$ \\
\hline $\mathrm{T} 32-50 \% 21 \mathrm{DAE}+50 \% 35 \mathrm{DAE}$ & $2.936 \mathrm{a}$ & $2.498 \mathrm{a}$ & $2.717 \mathrm{c}$ \\
\hline $\mathrm{T} 33-70 \% 21 \mathrm{DAE}+30 \% 35 \mathrm{DAE}$ & $2.805 \mathrm{a}$ & $2.604 \mathrm{a}$ & $2.705 \mathrm{c}$ \\
\hline $\mathrm{T} 34-30 \% 28 \mathrm{DAE}+70 \%$ 35DAE & $2.573 \mathrm{a}$ & $2.372 \mathrm{ab}$ & $2.473 \mathrm{~d}$ \\
\hline $\mathrm{T} 35-50 \% 28 \mathrm{DAE}+50 \% 35 \mathrm{DAE}$ & $2.449 \mathrm{a}$ & $2.700 \mathrm{a}$ & $2.560 \mathrm{~d}$ \\
\hline $\mathrm{T} 36-70 \% 28 \mathrm{DAE}+30 \%$ 35DAE & $2.849 \mathrm{a}$ & $2.614 \mathrm{a}$ & $2.732 \mathrm{c}$ \\
\hline Media & 2.859 & 2.485 & 2.672 \\
\hline $\mathrm{CV}(\%)$ & 12,0 & 15,1 & 13,9 \\
\hline
\end{tabular}

*Médias seguidas de mesma letra na coluna não diferem entre si pelo teste de Scott \& Knott, em nível de 5\% de probabilidade de erro.

plântulas, apresentou as menores produtividades, demonstrando não ser promissora para os grupos de feijoeiro estudados. Com exceção da produtividade de grãos, todas as outras características tiveram influências do fator cultivar.

\section{REFERÊNCIAS}

ARF, M.V. et al. Fontes e épocas de aplicação de nitrogênio em feijoeiro de inverno sob sistema plantio direto. Pesquisa
Agropecuária Tropical, v.41, n.3, p.430-438, 2011. Disponível em: <http://www.revistas.ufg.br/index.php/pat/article/view/9706/9728>. Acesso em: 15 dez. 2011.

BASSO, C.J.; CERETTA, C.A. Manejo do nitrogênio no milho em sucessão a plantas de cobertura de solo, sob plantio direto. Revista Brasileira de Ciência do Solo, v.24, n.4, p.905-915, 2000. Disponível em: <http://sbcs.solos.ufv.br/solos/revistas/v24n4a22. pdf $>$. Acesso em: 10 nov. 2009.

BAYER, C.; MIELNICZUK, J. Dinâmica e função da matéria orgânica. In: SANTOS, G. de A. et al. (Ed.). Fundamentos da

Ciência Rural, v.43, n.5, mai, 2013. 
matéria orgânica do solo: ecossistemas tropicais e subtropicais. 2.ed. Porto Alegre: Metrópole, 2008. p.7-18.

CABRAL, P.D.S. et al. Análise de trilha do rendimento de grãos de feijoeiro (Phaseolus vulgaris L.) e seus componentes. Revista Ciência Agronômica, v.42, n.1, p.132-138, 2011. Disponível em: <http://www.scielo.br/scielo.php?pid=S18066690201100010001 $7 \&$ script=sci_arttext $>$. Acesso em: 15 dez. 2011. doi: 10.1590/ S1806-66902011000100017.

CARVALHO, M.A.C. et al. Doses e épocas de aplicação de nitrogênio e teores foliares deste nutriente e de clorofila em feijoeiro. Revista Brasileira de Ciência do Solo, v.27, n.3, p.445-450, 2003. Disponível em: <http://www.scielo.br/scielo.php?script=sci_arttex t\&pid=S0100-06832003000300006>. Acesso em: 08 out. 2009. doi: 10.1590/S0100-06832003000300006.

COIMBRA, J.L.M. et al. Correlações canônicas : II - análise do rendimento de grãos de feijão e seus componentes. Ciência Rural, v.30, n.1, p.31-35, 2000. Disponível em: <http://www.scielo.br/ scielo.php?script $=$ sci_arttext $\&$ pid $=$ S0103-84782000000100005 $>$. Acessoem: 15 dez.2011. doi: 10.1590/S0103-84782000000100005.

COMISSÃO DE QUÍMICA E FERTILIDADE DO SOLO - RS/ SC. Recomendações de adubação e calagem para os estados do Rio Grande do Sul e Santa Catarina. 3ed. Passo Fundo, RS. SBCS, 2004. 400p.

COMISSÃO ESTADUAL DE PESQUISA DE FEIJÃO. Recomendações técnicas para o cultivo do feijão no Rio Grande do Sul. Erechim, RS, 2001. 112p.

COMISSÃO TÉCNICA SUL-BRASILEIRA DE FEIJÃO. Informações técnicas para o cultivo do feijão na Região Sul brasileira, 2009. Florianópolis: Epagri, 2010. 164p.

EMBRAPA (EMPRESA BRASILEIRA DE PESQUISA AGROPECUÁRIA). Centro Nacional de Pesquisa de Solos. Sistema brasileiro de classificação de solos. 2.ed. Rio de Janeiro, 2006. 306p.

EMBRAPA (EMPRESA BRASILEIRA DE PESQUISA AGROPECUÁRIA). Centro Nacional de Pesquisa Tecnológica em Informática para a Agricultura. SOC: Ambiente de software NTIA, versão 4.2.2: Manual do usuário - ferramental estatístico. Campinas, 1997. 258p.

HUNGRIA, M. et al. Assimilação do nitrogênio pelo feijoeiro. II. Absorção e translocação do $\mathrm{N}$ mineral e do $\mathrm{N}^{2}$ fixado. Revista Brasileira de Ciência do Solo, v.9, n.1, p.201-209, 1985.

MOREnO, J.A. Clima do Rio Grande do Sul. Porto Alegre: Secretaria da Agricultura, Diretoria de Terras e Colonização, Secção de Geografia, 1961. 46p.
NICOLOSO, F.T. Efeitos do nitrogênio mineral, molibdênio e inoculação na cultura do feijoeiro (Phaseolus vulgaris L.). 1989. 148f. Dissertação (Mestrado em Agronomia) - Universidade Federal de Santa Maria, Santa Maria, RS.

PALOMINO, E.C. et al. Efeito de épocas e doses da adubação nitrogenada em cobertura na cultura do feijoeiro, cultivar carioca semeado no período da seca. In: REUNIÃO BRASILEIRA DE FERTILIDADE DO SOLO E NUTRIÇÃO DE PLANTAS, 25., 2000, Santa Maria, RS. Anais... Santa Maria: XXV FertBio, 2000. 181-181.

ROSOLEM, C.A.; MARUBAYASHI, O.M. Seja o doutor do seu feijoeiro. Informativo Agronomico, v.68, p.1-16, 1994. (Encarte). Disponível em: <http://www.ipni.org.br/ppiweb/brazil.nsf/87cb8 a98bf72572b8525693e0053ea70/d5fbc829a2f54298832569f8004 695c5/\$FILE/Seja\%20Feijoeiro.pdf>. Acesso em: 15 out. 2009.

ROSOLEM, C.A. Nutrição e adubação do feijoeiro. Piracicaba, SP: POTAFOS, 1987. 93p.

SANT'ANA, E.V.P. et al. Eficiência de uso de nitrogênio em cobertura pelo feijoeiro irrigado. Revista Brasileira de Engenharia Agrícola e Ambiental, v.15, n.5, p.458-462, 2011. Disponível em: <http://www.scielo.br/pdf/rbeaa/v15n5/v15n5a04. pdf>. Acesso em: 13 dez. 2011.

SANTI, A.L. et al. Adubação nitrogenada na cultura do feijoeiro em plantio convencional. Ciência Rural, v.36, n.4, p.1079-1085, 2006. Disponível em: <http://www.scielo.br/scielo.php?script=sci_arttex t\&pid=S0103-84782006000400006>. Acesso em: 23 nov. 2009. doi: 10.1590/S0103-84782006000400006.

SORATTO, R.P. et al. Nitrogênio em cobertura no feijoeiro cultivado em plantio direto. Revista Brasileira de Ciência do Solo, v.30, p.259-265, 2006. Disponível em: <http://www.scielo.br/ scielo.php?script=sci_arttext $\&$ pid=S0100-06832006000200007>. Acessoem: 18 out. 2009. doi: 10.1590/S0100-06832006000200007.

SORATTO, R.P. et al. Níveis e épocas de aplicação de nitrogênio em cobertura no feijoeiro irrigado em plantio direto. Cultura Agronômica, v.10, n.1, p.1-12, 2001. Disponível em: <http:// www.revcultagr.feis.unesp.br/edicoes/pdf/edicao2001.pdf >. Acesso em: 08 out. 2009.

SOUZA, E.F.C. et al. Aplicação de nitrogênio e inoculação com rizobio em feijoeiro cultivado após milho consorciado com braquiária. Pesquisa Agropecuária Brasileira, v.46, n.4, p.370-377, 2011. Disponível em: <http://www.scielo. br/scielo.php?pid=S0100-204X2011000400005\&script $=$ sci_ abstract\&tlng=pt>. Acesso em: $15 \mathrm{dez}$. 2011. doi: 10.1590/S0100204X2011000400005. 